\title{
REFLEXÕES SOBRE APRENDER A DIZER A SUA PALAVRA EM CONTEXTO DE DIVERSIDADE EDUCACIONAL PARA A CIDADANIA
}

\author{
Reflections on learning to say your word in the context of educational diversity for \\ citizenship
}

Lillian Nobre Gois Pinheiro - FPCEUP/Portugal Luís Joaquim António Muengua - FPCEUP / Portugal

RESUMO: A palavra na educação Freireana assume um estatuto que supera o de mero suporte linguístico carregado de significados, comportando sentido e valor na relação dialogante, onde os saberes são contextualizados e as experiências assumidas como elementos que informam a relação educativa para a cidadania. A palavra deve ser capaz de transformar o sujeito desmistificando a ideia de educação bancária, para a emancipação deste, assumindo um caráter político (Freire, 2018) com ciência e ternura, boniteza e arte, no sentido de tornar as suas práticas como um exercício de libertação pelo cultivo da consciência crítica, ética e humana sobre as normas socialmente instituídas, a fim de "escutar os apelos que convocam (...) sempre mais além de seus limites" (Fiori, 2018, p. 15). Sendo a educação uma forma de intervenção no mundo realizamos a pesquisa a fim de percebermos como o estudante pode dizer melhor a sua palavra em contexto de diversidade educacional e como as Ciências da Educação contribuem para a autonomia com vista o alcance de uma educação libertadora e inclusiva. A partir dos paradigmas fenomenológico-interpretativo e sociocrítico, com recurso a pesquisa bibliográfica e a técnica de análise desses dados, os resultados apontam que a presença de um diálogo efetivo e a escuta conferem a centralidade aos estudantes, atende às particularidades e valoriza os saberes.

Palavras-chave: Educação Libertadora. Inclusão cidadã. Palavra e diálogo.

ABSTRACT: The word in Freirean education takes on a status that surpasses that of mere linguistic support laden with meanings, comprising meaning and value in the dialogical relationship, where knowledge is contextualized, and experiences are assumed as elements that inform the educational relationship for citizenship. The word must be able to transform the subject by demystifying the idea of banking education, for its emancipation, assuming a political character (Freire, 2018) with science and tenderness, beauty and art, in order to make their practices as an exercise of liberation through the cultivation of critical, ethical and human conscience about socially instituted norms, in order to "listen to the calls that summon (...) always beyond their limits" (Fiori, 2018, p. 15). As education is a form of intervention in the world, we carry out the research in order to understand how the student can better say his word in the context of educational diversity and how the Educational Sciences contribute to autonomy in order to achieve a liberating and inclusive education. Based on the phenomenological-interpretative and sociocritical paradigms, using bibliographic research and the technique of analyzing these data, the results indicate that the presence of an effective dialogue and listening give centrality to students, meets the particularities and values knowledge.

Keywords: Liberating Education. Citizen inclusion. Word and dialogue.

Educação, Psicologia e Interfaces, Volume 4, Número 2, p. 67-78, Abril/Junho, 2020.

ISSN: 2594-5343. DOI: 10.37444/issn-2594-5343.v4i2.265 


\section{INTRODUÇÃO}

Se, por um lado, a educação é, manifestamente, revestida de intenções políticas, por outro lado, ela deve manifestar-se descomprometida com as tendências de opressão dos aprendentes e traduzir-se por práticas que privilegiem a "ação com eles" e "não fazer para eles" (FREIRE, 2018, pp. 56-57), o que não passaria, por sinal, de uma ação de objetificação dos sujeitos por conta da desconsideração dos seus contributos e das suas experiências. Na relação educativa o estatuto que Freire atribui à palavra traduzirse-ia na ação de quem se manifesta - o mediador- continuamente disponível para a ouvir mais o outro - o sujeito -, do que se fazer ouvir, no sentido de permitir que o ato educativo emirja de uma relação participada e que valoriza os contributos dos sujeitos reafirmando a ideia do "círculo de cultura" (FIORI, 1994, p. 6).

Tendo em consideração estes pressupostos, construímos uma problemática cujas perspectivas emergem a partir do campo das Ciências da Educação, onde orientamos o questionamento no sentido de procurarmos perceber em que medida os mecanismos adotados para a criação de contextos educacionais mais inclusivos, emancipadores e humanizados se constituem como indutores conducentes ao exercício de cidadania plena pelo estudante.

A partir de uma dupla hermenêutica compreendemos como um contributo das Ciências da Educação a fundamentação da importância das relações de aproximação entre ciência e experiência considerando não só o sujeito, mas o coletivo valorizando o diálogo e o amor, a dialética e o conflito a fim de serem superados os estabelecimentos de manifestações de poder nas relações educativas. Constitui-se, então, uma construção de conhecimento e aprendizagem política-educativa em que busca não só o significado, mas o sentido de dizer a palavra.

É por compreendermos que a educação constitui uma forma de intervenção no mundo que realizamos a pesquisa, com a expectativa de procurarmos perceber as possibilidades de o estudante dizer melhor a sua palavra em contexto de diversidade educacional, onde conjugamos, através de uma análise crítica e reflexiva, as produções epistemológicas das Ciências da Educação e a forma como estas podem contribuir para que o estudante desenvolva a autonomia e a emancipação cidadã com vista ao alcance de uma educação mais libertadora e inclusiva, que se manifeste profundamente comprometida com as questões de equidade, qualidade e justiça social.

Educação, Psicologia e Interfaces, Volume 4, Número 2, p. 67-78, Abril/Junho, 2020. 
Reflexões sobre aprender a dizer a sua palavra em contexto de diversidade educacional para a cidadania

\section{ABORDAGEM METODOLÓGICA}

Reconhecendo que a educação é um campo de fluxos e de mestiçagens que acabam configurando o processo e a relação educativos, nos propusemos levar a cabo um estudo que prima por uma abordagem de natureza qualitativa, socorrendo-se dos pressupostos epistemológicos dos paradigmas fenomenológico-interpretativo e sociocrítico. A adoção dos pressupostos epistemológicos do paradigma fenomenológico-interpretativo prende-se com o fato de pretendermos desenvolver uma reflexão focada para o campo da educação e que emerge deste, por um lado, e por reconhecermos a "complexidade do fenômeno educativo" (AMADO, 2017, p. 28).

A opção pelo paradigma sociocrítico conjuga-se, também, com a pretensão de criarmos uma dialética epistemológica (HABERMAS, 1989), reconhecendo que a análise das problemáticas no campo da educação pressupõe reconhecer que os fluxos e as mestiçagens também enformam os fenómenos, razão pela qual entendemos que uma única perspectiva epistemológica não é abrangente. Deste modo, os pressupostos do paradigma sóciocrítico permitiram-nos construir reflexões sobre a necessidade de “desmascarar as ideologias e a situação de opressão e de dominação" (AMADO, 2017, p. 54) num contexto educativo em que os "conflitos de interesses e de poder" AMADO, 2017, p. 54) são sutis e, simultaneamente, eficientes.

A estratégia de recolha de dados foi corporizada pelas técnicas da pesquisa bibliográfica, via pela qual acedemos a um leque de registos sobres as reflexões "a partir das contribuições dos autores dos estudos" precedentes (SEVERINO, 2007, p. 122) sobre as diversas temáticas e problemáticas em educação, conjugando com a preocupação que permitisse relacionar as perspetivas dos autores sobre as oportunidades educacionais e educativas para que os estudantes em sua diversidade, quer sejam negros, homossexuais, estrangeiros e/ou com Necessidades Especiais (NE), ocupem o seu lugar cidadão no mundo com autonomia e emancipação ao aprender a dizer a sua palavra.

\section{RESULTADOS E DISCUSSÃO}

Os dados recolhidos enunciam que a palavra para Paulo Freire é tão importante como o seu falante e a necessidade que este tem de expressar as suas ideias, dado que a

Educação, Psicologia e Interfaces, Volume 4, Número 2, p. 67-78, Abril/Junho, 2020.

ISSN: 2594-5343. DOI: 10.37444/issn-2594-5343.v4i2.265 
palavra não se traduz pela simples exteriorização das ideias, mas pela totalidade dos elementos que a geram e a constituem. Assim, se a palavra não se esgota em si mesma, na medida em que ela comporta experiências e saberes dos sujeitos, urge, a partir daí, questionar porquê é que a comunicação na relação educativa continua a evoluir como algo que está fora dos sujeitos, enquanto "são [a própria] comunicação" (FREIRE, 2018, p. 126), se a escola continua a emitir um discurso que aparenta um compromisso de 'oferecer' à sociedade indivíduos verdadeiramente úteis e altamente criativos.

Deste modo, se a presença de um diálogo efetivo contribui para uma relação educativa frutífera e que possibilita, pela via da palavra, a socialização da relação entre os sujeitos e o conhecimento, porquê é que a escuta continua a ser encarada como um privilégio e faculdade detida por uma pessoa? Esta problematização resulta do fato de entendermos que o diálogo efetivo é aquele que confere a centralidade aos estudantes, atende às particularidades dos sujeitos e à valorização dos saberes destes, possibilitando a emancipação cidadã efetiva, derivada do fato de o sujeito da educação participar na construção do saber.

Os aspectos mencionados sobre a capacidade da escuta denunciam alguma postura excludente, visto que a prática de uma educação libertadora não reside, simplesmente, no fato de a escola e o educador assumirem práticas que conferem a centralidade ao sujeito. Passa, também, pela predisposição da escola/educador em aceitarem ser transformados pelo sujeito, o que, por si, seria um forte indicador da emancipação e de exercício de cidadania por estes, assim como uma manifesta preocupação da escola em não assumir o ‘pedagogismo opressor’ (LIMA, 2019).

\subsection{A palavra e a relação educativa}

Emitir reflexões sobre a aprendizagem é um exercício que remete e requer um hibridismo crítico contínuo e sistematicamente ponderado, na medida em que exige, da parte de quem produz ou emite as reflexões, a necessidade de cultivar um olhar que atenta para os sujeitos, para as margens e para o que pode manifestar-se como sendo aparentemente periférico (CORREIA, 1998).

Deste modo não estar-se-ão, somente, sendo criadas as condições para que seja conhecido o periférico, mas que, a partir daí, sejam criados os mecanismos de conhecimento e acesso à centralidade, dado que a palavra, nos contextos educativos, é 
Reflexões sobre aprender a dizer a sua palavra em contexto de diversidade educacional para a cidadania

assumida por Paulo Freire como sendo tão importante quão o seu falante e a necessidade que este tem de expressar as suas ideias. A palavra é um enunciador de diálogo e denunciador do mesmo, na medida em que passa a ser pela via da palavra que a comunicação efetiva se torna tangível e permite desenvolver um mecanismo para instituir a dialética no diálogo.

Como refere Freire (2002) considerando o saber da experiência de vida e de mundo dos sujeitos não se estabelece uma relação educativa de construção do aprender a dizer a palavra senão pelo diálogo meio em que ao desafiar o educando"a pensar sua história social (...) vai revelando a necessidade de superar certos saberes que, desnudados, vão mostrando sua "incompetência" para explicar os fatos" (FREIRE 2002, p. 30) problematizando e estimulando a curiosidade e a capacidade de ir além das condicionantes dos saberes da experiência e da ciência.

Logo, a palavra não é uma simples exteriorização das ideias, mas um mecanismo através do qual são expressos os elementos gerados pela intenção de comunicar e manifestados os anseios cognitivos do sujeito, razão pela qual, para a apreensão dos significados das mesmas palavras, se torna relevante dirigir a atenção para as "manifestações periféricas, às quais empresta a força inibidora" (Freire, 2018, p. 99), de modo a que se possa descortinar numa atitude crítica, o aparentemente visível ou supostamente óbvio.

Tal postura possibilitaria a "qualifica[ção dos] conhecimentos [aparentemente] profanos" (SILVA, 2010, p. 119) passando estes a adquirir "o estatuto de conhecimentos transformadores", uma vez que são valorizadas e continuamente mobilizadas as experiências e saberes dos sujeitos (FREIRE, 2018). A valorização das experiências dos sujeitos não deve ser assumida como uma tentativa "de sacralizar estes saberes, mas sim de os reconhecer na sua legitimidade contextual [dado que] as interpretações que os sujeitos fazem, também se propõe a sua visibilidade de uma certa maneira" (SILVA, 2010, pp. 118-119).

Neste seguimento, uma educação que não prima pela visibilidade dos sujeitos e pela centralidade destes é opressora, não se manifesta "implica[da com] um pensar crítico [e] capaz, também de gerá-lo" (FREIRE, 2018, p. 88) num processo de diálogo verdadeiro, efetivo e comprometido com a libertação dos atores educativos. 
A palavra na filosofia de educação de Paulo Freire assume um estatuto que supera o de mero suporte linguístico carregado de significados. É, pois, carregada de sentido e valor que são traduzidos e ressignificados na relação comunicativa e dialogante entre sujeito-mediador que corporizam o ato educativo e o processo de aprendizagem, através da contextualização dos saberes e da mobilização das experiências dos sujeitos, enquanto elementos fundamentais para a conformação do empreendimento educativo.

Ao se mobilizar o sujeito e as suas experiências estarão sendo preparadas as condições para torná-lo ativo nos processos de construção do conhecimento e no desenvolvimento de competências para a cidadania, visto que a educação passará a representar "um contributo indispensável à humanização dos seres humanos e à realização da sua vocação intelectual, através da interpretação crítica do mundo e da participação ativa no processo de sua transformação" (LIMA, 2019, p. 16).

Aqui, a palavra deve ser capaz de transformar o sujeito e desmistificar a ideia de uma educação bancária, centrada nos conteúdos e fortemente atrelada aos desígnios do currículo formal, perspectiva esta que dará lugar a emergência de um modelo de educação que se manifesta comprometido com a emancipação do sujeito. Assim, a educação estará a assumir um caráter político (FREIRE, 2018) com ciência e ternura, com boniteza e arte, ao tornar as suas práticas como um exercício de libertação do sujeito por via do cultivo de uma consciência crítica, ética e humana e de questionamento contínuo sobre as normas social ou politicamente instituídas a fim de passar a "escutar os apelos que convocam (...) sempre mais além de seus limites" (FIORI, 2018, p. 15) formais ou normalizados.

É crucial frisar que as normas que emergem dos contextos social ou político são, geralmente, legitimadas pela escola, enquanto instituição a qual a sociedade confere a finalidade de formar os indivíduos, na medida em que cabe à escola "contribuir para a resolução quer de problemas de carácter educativo quer de problemas de carácter social" (TRINDADE, 2009, p. 33).

Embora reconhecemos, por um lado, a função social da escola, reiteramos, por outro lado, que o ato de aprender não pressupõe, somente, a aquisição do saber numa relação dogmática onde existe quem detém o conhecimento - o mestre - e que ensina ao outro - o aprendiz. 
Reflexões sobre aprender a dizer a sua palavra em contexto de diversidade educacional para a cidadania

Pelo contrário, a materialização de um ato educativo que se manifeste comprometido com a libertação do sujeito requer, sim, o cultivo de uma postura pedagógica cuja relação perspective o desenvolvimento e emancipação do sujeito da aprendizagem, no sentido em que os conteúdos da aprendizagem não são concebidos para o sujeito, mas sim com o sujeito numa ação de interatividade permanente (FREIRE, 2018), dado que "o saber não poderá ser considerado como um produto das relações de poder" (TRINDADE, 2009, p. 33). Para o efeito, urge compreender que a concepção e práticas de educação não devem "assumir uma dimensão eminentemente prescritiva do ato educativo" (TRINDADE, 2009: 34), como se estivéssemos perante uma receita de culinária cuja combinação dos ingredientes dará lugar à um produto pronto para consumir.

Tal como refere Fiori (2018, p. 14), ao partilhar a abordagem sobre o "aprender a dizer a sua palavra", a educação não pode assumir uma relação pedagógica de dominação, no sentido de assentar no pressuposto de "pedagogia para ele". Deve, sim, primar por uma relação de dialética comunicativa que permita empreender uma pedagogia que seja dele e concebida com ele. Tal postura, ao considerar a cultura, a experiência e os conhecimentos dos sujeitos da aprendizagem, irá se constituir como "um contínuo retomar reflexivo de seus próprios caminhos de libertação - não será simples reflexo, mas reflexiva criação e recriação, um ir adiante nesses caminhos" (FIORI, 2018, p. 14).

Logo, a adoção dos pressupostos da reflexividade e da recriação constituir-se-á como um elemento que possibilita a libertação dos atores envolvidos no processo de coconstrução da aprendizagem, na medida em que, quer seja o orientando assim como o orientador, passarão a estar, por via da palavra que emerge do diálogo efetivo, munidos de ferramentas que lhes permitam identificar e reconhecer as potencialidades de cada um. O diálogo efetivo permite, ainda, o desenvolvimento de mecanismos que contribuem para que a relação de aprendizagem não seja configurada pelo esforço de dominar o outro, mas sim da mobilização de elementos que concorram para que se erga um ambiente co-libertador para ambos, minimizando, senão eliminando, os processos tendencialmente marcados pelos chavões opressores e manifestamente aniquiladores da capacidade reflexiva e crítica.

Educação, Psicologia e Interfaces, Volume 4, Número 2, p. 67-78, Abril/Junho, 2020.

ISSN: 2594-5343. DOI: 10.37444/issn-2594-5343.v4i2.265 
Nesse contexto, podemos relacionar o caráter político-educativo com a boniteza da capacidade de nós "como seres históricos (...), intervindo no mundo, conhecer o mundo" (FREIRE, 2002, p. 11) e produzir conhecimento crítico sobre ele. Essa forma de estar pode ser desenvolvida no "ensinar, aprender e pesquisar" que, na relação de mediação docência-discência, deve-se configurar fundamental tanto "conhecer o conhecimento existente quanto saber que estamos abertos e aptos à produção do [novo] conhecimento" e que esse último "supera outro que antes foi novo e se fez velho e se ‘dispõe' a ser ultrapassado por outro amanhã” (FREIRE, 2002, p. 11). Esse processo do ciclo gnosiológico enfatiza que a relação docência-discência e a pesquisa são indicotomizáveis e essenciais ao estímulo à curiosidade epistemológica.

\subsection{Contributo das Ciências da Educação à discussão do sentido da palavra}

O contributo das pesquisas em Ciências da Educação tem demarcado, de forma cristalizada, a sua pertinência nas políticas e nos processos educativos, ao evidenciar e reiterar a necessidade de se considerar as experiências do sujeito, a importância da dialética na relação comunicativa e na construção do saber.

Assim, a dialeticidade e complexidade a partir das Ciências da Educação nos permite compreender como são construídas as relações dos sujeitos com os fenómenos sociais, políticos, educativos e a própria história da humanidade numa luta de contrários "em que a realidade é unidade e multiplicidade e está articulada com os fenómenos em que está inserida, ou seja, [está constantemente] em transformação" (SEVERINO, 2007, p. 116). Os pensadores dessa ordem deixam claro que não há como dissociar a análise das práticas dos sujeitos da ação histórica e social, porque "nunca é uma questão apenas de saber, mas também de poder" (SEVERINO, 2007, p. 116) o que torna fundamental a conscientização, o diálogo e a politização para lutar criticamente contra os opressores.

Tal como anota Charlot (2006, p. 9), as Ciências da Educação estão imbuídas de uma mestiçagem, na medida em que é manifestamente permeável à circulação e cruzamento de várias áreas do saber, o que lhe permite problematizar e "afrontar a complexidade e as contradições características da contemporaneidade".

Esta componente mestiça das Ciências da Educação constitui-se como um elemento enriquecedor, na medida em que remete o pesquisador para que cultive,

Educação, Psicologia e Interfaces, Volume 4, Número 2, p. 67-78, Abril/Junho, 2020. 
Reflexões sobre aprender a dizer a sua palavra em contexto de diversidade educacional para a cidadania

sistematicamente, "uma atitude de vigilância crítica" (CANÁRIO, 2005, p. 32) resultante "da proximidade entre o conhecimento produzido" por quem pesquisa em Educação "e o conhecimento produzido pelos" atores educativos, o que requererá, em termos de ação investigativa, a necessidade de abandono da tendência que circunscreve o ato de pesquisar "a uma função instrumental relativamente a encomendas do poder" (CANÁRIO, 2005, p. 33).

Isto equivale a dizer que investigar em Ciências da Educação pressupõe formular as questões a partir do contexto em que ocorrem os fenômenos em estudo, de modo a que possamos nos familiarizar com a "maneira como eles são espontaneamente equacionados pelos atores" educativos numa "dupla hermenêutica, na medida em que [a produção do conhecimento científico esteja] próxima e não apareça como totalmente estranha à experiência dos atores" (CANÁRIO, 2005, p. 34).

Neste sentido, a 'dupla hermenêutica' irá conferir uma outra configuração à palavra, dado que esta palavra, como alude Vygotsky (2001), "refere-se sempre a todo um grupo ou a todo um conjunto de objectos, e não a um qualquer objecto isolado" (26), passando ela mesma a se instituir como um elemento que se manifesta predisposto a combater a "relação de dominação" (FREIRE, 2018, p. 85) por conta da consideração da totalidade, erguendo-se como "fundamento do diálogo, do amor" e de distanciamento para com os enunciadores que emergem do "pretexto para a manipulação" (FREIRE, 2018, p. 85).

Assim, a palavra no diálogo educativo está revestida de uma importância que transcende a vontade dos sujeitos, na medida em que passa a ser instituidora do próprio diálogo visto que a falta de uma apropriação efectiva da palavra não só compromete a "comunicação e verdadeira educação", assim como pode aniquilar o esforço de “superação da contradição educador-educandos” (FREIRE, 2018, p. 88).

Uma vez que "o significado é uma parte indissociável da palavra [, visto que] a palavra sem significado, não é palavra, mas sim um som vazio" destituído de sentido (VYGOTSKY, 2001, p. 27)

Caberá às Ciências da Educação, no seu empreendimento epistemológico, identificar o sentido e o significado das palavras no processo educativo através de uma ação investigativa que permita desocultar as tentativas de aprisionamento ou 
condicionamento do diálogo educativo, por conta de posturas e práticas que se podem compromoter o alcance de uma educação libertadora.

\section{CONSIDERAÇÕES FINAIS}

A partir desse estudo tiramos algumas ilações que referem que a palavra continua sendo um elemento que configura as relações e o exercício de poder na relação educativa, devido ao aniquilamento do sentido crítico da educação, o que compromete, por conseguinte, o alcance dos pressupostos da educação libertadora e inclusiva, daí que a postura do mediador educativo se afigura importante no processo de ensinar e aprender a dizer a palavra.

Nesse sentido as Ciências da Educação contribuem para o desenvolvimento do pensamento crítico, dialógico e politizado, problematizados por Paulo Freire, na medida em que permitem que a partir de várias áreas do saber possamos compreender as relações dos sujeitos com a sociedade e intervir na transformação do mundo a partir da educação e do ensinar-aprender a dizer a sua palavra.

Portanto, fica evidente a necessidade de fomento de iniciativas para pesquisar, praticar e aproximar mais a universidade das escolas, a sociedade das instituições educacionais, e que juntas troquem ensinamentos e aprendizagens para uma educação cidadã com amor e justiça social, inclusiva, equitativa e qualitativa. Que haja mais acolhimento e acompanhamento aos estudantes em sua diversidade nas instituições educacionais e que sejam criados espaços para que eles ocupem o seu lugar de reivindicação, (re)invenção e exercício de seus direitos.

\section{REFERÊNCIAS BIBLIOGRÁFICAS}

AMADO, João. A Investigação em educação e seus paradigmas. In Amado, João (Coord.). Manual de Investigação Qualitativa em Educação. $3^{\text {a }}$ Edição (pp. 21-73). Coimbra: Imprensa da Universidade de Coimbra, 2017.

ARAÚJO, Helena. Cidadania na sua polifonia: Debates nos estudos da educação feminista. Educação, Sociedade e Culturas, (25) 83-116, 2007. Disponível em: https://www.fpce.up.pt/ciie/revistaesc/ESC25/HelenaAraujo.pdf Acesso em 2 maio 2019.

CANÁRIO, Rui. O que é a escola? Um “olhar" sociológico. Porto: Porto Editora, 2005.

Educação, Psicologia e Interfaces, Volume 4, Número 2, p. 67-78, Abril/Junho, 2020.

ISSN: 2594-5343. DOI: 10.37444/issn-2594-5343.v4i2.265 

cidadania

CHARLOT, Bernard. A pesquisa educacional entre conhecimentos, políticas e práticas: especificidades e desafios de uma área de saber. Rev. Bras. Educ., Rio de Janeiro, v. 11, n. 31, p. 7-18, abr. 2006. Disponível em:

<http://www.scielo.br/scielo.php?script=sci_arttext\&pid=S1413-

$24782006000100002 \& \operatorname{lng}=$ en\&nrm=iso>. Acesso em 02 fev. 2019.

https://doi.org/10.1590/S1413-24782006000100002.

CORREIA, José, A.. Para uma Teoria Crítica em Educação. Porto: Porto Editora, 1998.

FIORI, Ernani. Prefácio da edição original: Aprender a dizer sua a palavra. In Freire, Paulo. Pedagogia do oprimido. (pp. 13-24). Porto: Edições Afrontamento, 2018.

FREIRE, Paulo. Pedagogia da autonomia: saberes necessários à prática educativa. $25^{a}$ edição. São Paulo: Paz e Terra (Coleção Leitura), 2018.

FREIRE, Paulo. Pedagogia do oprimido. $3^{\text {a }}$ Edição. Porto: Edições Afrontamento, 2018.

HABERMAS, Jürgen. Consciência moral e agir comunicativo. In: PORTELA, Eduardo; LEÃO, Emmanuel; SODRÉ, Moniz; BAYER, Gustavo (Coord.). Consciência moral e agir comunicativo. Rio de Janeiro: Tempo Brasileiro, 1989.

LIMA, Licínio. A pedagogia do oprimido como fonte para a crítica do pedagogismo opressor. Educação, Sociedade e Culturas (54) 11-29, 2019. Disponível em: http://repositorium.sdum.uminho.pt/handle/1822/62554 Acesso em dez 2019.

SEVERINO, António. Metodologia do trabalho científico. $23^{\text {a }}$ Edição. São Paulo: Cortez Editora, 2007.

SILVA, Sofia. Da casa da juventude aos confins do mundo. etnografia de fragilidades, medos e estratégias juvenis. porto: edições afrontamento, 2010.

TRINDADE, Rui. escola, poder e saber: A relação pedagógica em debate. Porto: Livpsic, 2009.

VYGOTSKY, Lev. Pensamento e linguagem. Vila Nova de Gaia: Estratégias Criativas, 2001.

\section{Credenciais da/os autora/es}

PINHEIRO, Lillian Nobre Gois. Doutoranda em Ciências da Educação na Faculdade de Psicologia e Ciências da Educação da Universidade do Porto (FPCEUP) Portugal. Mestra em Ciências da Educação na FPCEUP. Graduada em Administração Pública na Universidade Estadual de Alagoas (UNEAL) - Alagoas, Brasil. (D) Orcid: 0000-00020935-3756 E-mail: lillian_nobre@ hotmail.com

Educação, Psicologia e Interfaces, Volume 4, Número 2, p. 67-78, Abril/Junho, 2020.

ISSN: 2594-5343. DOI: 10.37444/issn-2594-5343.v4i2.265 
MUIENGUA, Luís Joaquim António. Doutorando em Ciências da Educação na Faculdade de Psicologia e Ciências da Educação da Universidade do Porto (FPCEUP) Portugal. Mestre em Ciências da Educação pela FPCEUP. Licenciado em Ensino de Desenho pela Universidade Pedagógica - Maputo, Moçambique. (D) Orcid: 0000-00024246-9160 E-mail: luismuiengua@gmail.com

Como citar este artigo (Formato ABNT): PINHEIRO, Lillian Nobre Gois; MUENGUA, Luís Joaquim António. Reflexões sobre aprender a dizer a sua palavra em contexto de diversidade educacional para a cidadania. Educação, Psicologia e Interfaces, v. 4, n.2, p. 67-78, 2020. Doi: 10.37444/issn-2594-5343.v4i2.265

Recebido: 09/01/2020.

Aceito: 29/03/2020. 